\title{
Measuring the expected synergy in Spanish regional and national systems of innovation
}

\author{
Loet Leydesdorff ${ }^{1}$ (D) Igone Porto-Gomez $^{2}$ (D)
}

Published online: 24 August 2017

(C) The Author(s) 2017. This article is an open access publication

\begin{abstract}
This paper examines the effect of synergy at the geographical, technological, and organizational levels on the structure of the innovative system in Spain. Using a unique dataset of more than one million firms in 2010 across geographic regions in Spain, it empirically estimates the synergy within and across regions and sectors. The key findings indicate that Spain's innovation system is largely decentralized into more regionalized systems with the strongest role played by the metropolitan areas. The results have policy implications for Spain as well as other nations and intra-country regions. The paper contributes to the extant literature related to innovation systems in three ways: first, by using a more novel approach adapting the triple helix context; second, by providing empirical evidence on the importance of synergy in influencing the structure of a national innovation system; and third, by providing a case study of Spain.
\end{abstract}

Keywords Region · Innovation · Synergy · Triple helix · Spain · Barcelona

JEL Classification $\mathrm{O} 32 \cdot \mathrm{O} 14 \cdot \mathrm{R} 58$

\section{Introduction}

After a visit to Japan, Freeman $(1987,1988)$ noted that Japan could be considered as a national system of innovations (NSI). Lundvall (1992) and Nelson (1993) elaborated further on this concept using case studies. Lundvall (1988) had argued that interactions

Loet Leydesdorff

loet@leydesdorff.net

Igone Porto-Gomez

igone_porto001@ehu.eus

1 Amsterdam School of Communication Research (ASCoR), University of Amsterdam, P.O. Box 15793, 1001 NG Amsterdam, The Netherlands

2 Engineering School of Bilbao, University of the Basque Country (EHU-UPV), Alameda Urquijo s/n, 48013 Bilbao, Spain 
within national contexts might be more effective than across borders. However, one can ask whether some borders-for example between Scandinavian countries or EU member states - can still be characterized as national, and one can also question whether regions within nations may function as systems of innovation (Braczyk et al. 1998; Cooke, 2002). Is Italy, for example, a single innovation system, or does Italy as a nation-state house different innovation models in northern and southern Italy (e.g., Balconi et al. 2004; Biggiero 1998)? Have regions with relative autonomy, such as Scotland or Catalonia, increasingly been able to construct innovation systems in terms of competitive advantages (Cooke and Leydesdorff 2006)?

Some authors have strongly argued for studying regional innovation systems (e.g., Braczyk et al. 1998; Cooke 2002; cf. Boschma 2005) while others have continued to focus on nations as units of analysis. Carlsson (2006) discusses also other options such as sectorial innovation systems. In this study, we do not aim to discuss the advantages or disadvantages of these perspectives, but consider them as possible definitions and pursue a comparative analysis for Spain as a specific case study. In our opinion, what counts as an innovation system should not be determined on the basis of normative definitions, but be entertained as an empirical question. Is innovativeness indicated at the regional and/or national level? How can one operationalize and measure innovation-systemness (e.g., Oh et al. 2016; Ritala and Almpanopoulou 2017)?

In a system, components and elements are concerted and a tendency towards equilibrium can be expected to prevail. One can test systemness, for example, in terms of the Markov property (e.g., Leydesdorff and Oomes 1999). In an innovation system, however, equilibrium is continuously upset because of the knowledge-based specification of new options (Nelson and Winter 1982; Schumpeter [1939], 1964). We argue that systems are innovative insofar as they generate new options from synergies among geographical, technological, and organizational factors (Edquist 1997; Storper 1997; Schwartz 2006). Synergy favors the entrepreneurial climate for innovation by reducing risks (selection) and generating options (variation). We propose to measure synergy in terms of redundancy using an indicator developed in the Triple-Helix context (Leydesdorff 2003). We elaborate this approach for the case of Spain (Buesa et al. 2006; Navarro and Gibaja 2012; ZabalaIturriagagoitia et al. 2007).

Redundancy plus uncertainty (or Shannon-type information) constitutes the maximum entropy of a system. Consequently, increased redundancy reduces relative uncertainty (Brooks and Wiley 1986). Redundancy can also be considered as options that have not (yet) been realized, whereas uncertainty provides a measure of the options that have already been realized. The latter options can be observed historically, whereas the dynamics of redundancy are evolutionary. However, we are able to specify an expectation. In practice, the dynamics of information and redundancy can reduce or add to the uncertainty that prevails; the trade-off can be measured using information theory.

Our measurement instrument—-to be elaborated below-was developed for the measurement of innovation systems in the Triple Helix (TH) context of studying universityindustry-government relations; but it can also be used outside this context. On the basis of Nelson et al.'s (2011) specification of the dynamics of innovation in medicine, Petersen et al. (2016), for example, generalized the TH model to "supply," "demand," and "control" as three sub-dynamics of innovation. In this study, and following up on a number of similar studies of nations, we use geographical, organizational, and technological distributions of firm characteristics and their mutual information. When the resulting indicator is positive, the historical dynamics prevail and options are exploited. However, when the resulting indicator is negative, uncertainty is reduced and synergy_operationalized as the 
generation of new options-is indicated more than past performance. Options become then available in the system for exploration (Kauffman 2000). When feedback and feedforward loops propel information in clockwise or counter-clockwise cycles with potentially opposite signs, the loops among three dimensions can also be self-reinforcing or "autocatalytic" (Ulanowicz 2009; Ivanova and Leydesdorff 2014).

Spain is an interesting case because after the end of the dictatorship (1975), a new constitution was drafted in 1978 which gave more autonomy to the regions. Two regions particularly - Catalonia and the Basque Country-have national aspirations because of their languages and their in some respects different positions within Spain and the European Union (Cooke and Morgan 1992; Buesa et al. 2006; Moso and Olazaran 2002; RibaVilanova and Leydesdorff 2001). In which respects (e.g., sectors) can Spain nevertheless be considered as a national system of innovations, or have regions been able to construct their own innovation systems; and if so, to what degree?

We analyze the Spanish national and regional innovation systems in terms of the expected synergies at NUTS2 (19 regions) and NUTS3 (51 provinces) levels. Synergy is operationalized as generating options for further development among distributions of firm characteristics $(N \approx 1 \mathrm{M})$. Regionalization has been an objective in Spain since the constitution of 1978. Our results indicate that five regions are central: Barcelona in Catalonia, Madrid and its immediate environment, Andalusia, the Valencian Community, and the Basque Country. Barcelona and Madrid stand out as metropolitan innovation systems. The Andalusian innovation system is concentrated in Seville. Synergy generation in the Valencia region and the Basque Country is lower than in the two metropoles by more than an order of magnitude. The national level adds marginally to the sum of regional systems except for the case of high-tech manufacturing. In sum, the national system of innovations is multi-centered with a focus on cities more than regions.

\section{Methodology}

\subsection{Data}

Data was downloaded from the ORBIS database of Bureau van Dijk on January 18, 2017. We first contacted Statistics Spain asking for the complete set of firm data-having received this information for the cases of Norway, Sweden, and Italy-but access was denied for administrative reasons. Within ORBIS, we used the string "All active companies and companies with unknown situation" combined (with a Boolean AND) with "World Region/Country/Region is country: Spain." ORBIS reports that 4,508,010 records are found as a search result (among $173 \mathrm{M}$ firms worldwide), but the retrieval contains only 2,520,000 records. These were downloaded in 18 batches of 140,000 records. Employment information, however, is not available ("n.a.") in 1,393,856 of these records; 1,073,452 firms are not assigned to a NACE code; and 55,264 firms are not listed with an address - that is, either a postcode or a city name. In summary, 1,508,984 (59.9\%) of the retrieved records are not complete in one of the three relevant dimensions, so that $1,011,016$ records provide the sample under study. ${ }^{1}$ In a comparable study about Italy,

\footnotetext{
1 Within this sample only $2.6 \%$ of the records have no turnover information, while this is the case in $74.2 \%$ of the discarded records.
} 
Cucco and Leydesdorff (2013) retrieved 992,172 firms registered at ORBIS, of which 462,316 contained the full information. ${ }^{2}$

Spain is organized into 19 regions ("autonomous communities") at the NUTS2 level and 51 provinces at the NUTS3 city level. We used postal codes to organize the data into these NUTS2 and NUTS3 regions. ${ }^{3}$ The distribution of the firms over NUTS2 and NUTS3 is provided in the left columns of Tables 3 and 5 (in the Results section), respectively. Figure 1 shows the administrative organization of the country in NUTS2 and NUTS3 classifications for the orientation of the reader.

Although geographical proximity tends to contribute to better links between the players located in a given environment (Knoben and Oerlemans 2006; Carboni 2013), the quality of these ties depends on several other indicators, such as the type of sector (Woerter 2012) and the size of the firm. Following Storper's (1997, p. 27) "Holy Trinity" of relations among geography, technology, and organization-we distinguish these three dimensions (Edquist 1997). The classification of firms in terms of the "Nomenclature générale des Activités économiques dans les Communautés Européennes" (NACE), Rev. 2 is used for indicating the (second) technological dimension. ${ }^{4}$ We disaggregate along this dimension in term of medium- and high-tech manufacturing, and knowledge-intensive services. Table 1 provides the list of NACE codes associated with these sectors in the economy.

In the third dimension, the number of employees can be used as a proxy for the organizational classification (Table 2). We could have used yearly turnover which is available for 1,147,048 of the records - that is, for almost the same subset. However, turnover rates vary among years more than numbers of employees. The distinction between small, medium, and large enterprises is standardized (for example, by Eurostat) ${ }^{5}$ as follows:

- micro enterprises: with fewer than 10 persons employed;

- small enterprises: with 10-49 persons employed;

- medium-sized enterprises: with 50-249 persons employed;

- small and medium sized enterprises (SMEs): with 1-249 persons employed;

- large enterprises: with 250 or more persons employed.

We first experimented with this classification, but then decided to use the finer-grained classes provided in Table 2 because this scheme produced richer results (Leydesdorff et al. 2006; Rocha 1999). Note that so-called micro-enterprises with fewer than 10 employees constitute $81.3 \%$ of the firms under study.

\footnotetext{
${ }^{2}$ Using the full set of data of Statistics Italy $(n=4,480,473)$, the results for the indicator were not significantly different (Spearman's $\rho=0.998 ; p<.01$ ).

3 NUTS is an abbreviation for "Nomenclature des Unités Territoriales Statistiques" (that is, Nomenclature of Territorial Units for Statistics). The NUTS classification is a hierarchical system for dividing up the economic territory of the EU.

4 The NACE code can be translated into the International Standard Industrial Classification (ISIC) that is used, for example, in the USA.

5 This classification is available, for example, at http://ec.europa.eu/eurostat/web/structural-businessstatistics/structural-business-statistics/sme?p_p_id=NavTreeportletprod_WAR_NavTreeportletprod_INST ANCE_vxlB58HY09rg\&p_p_lifecycle=0\&p_p_state=normal\&p_p_mode=view\&p_p_col_id=column-2\&p_ p_col_pos $=1 \&$ p_p_col_count $=4$.
} 


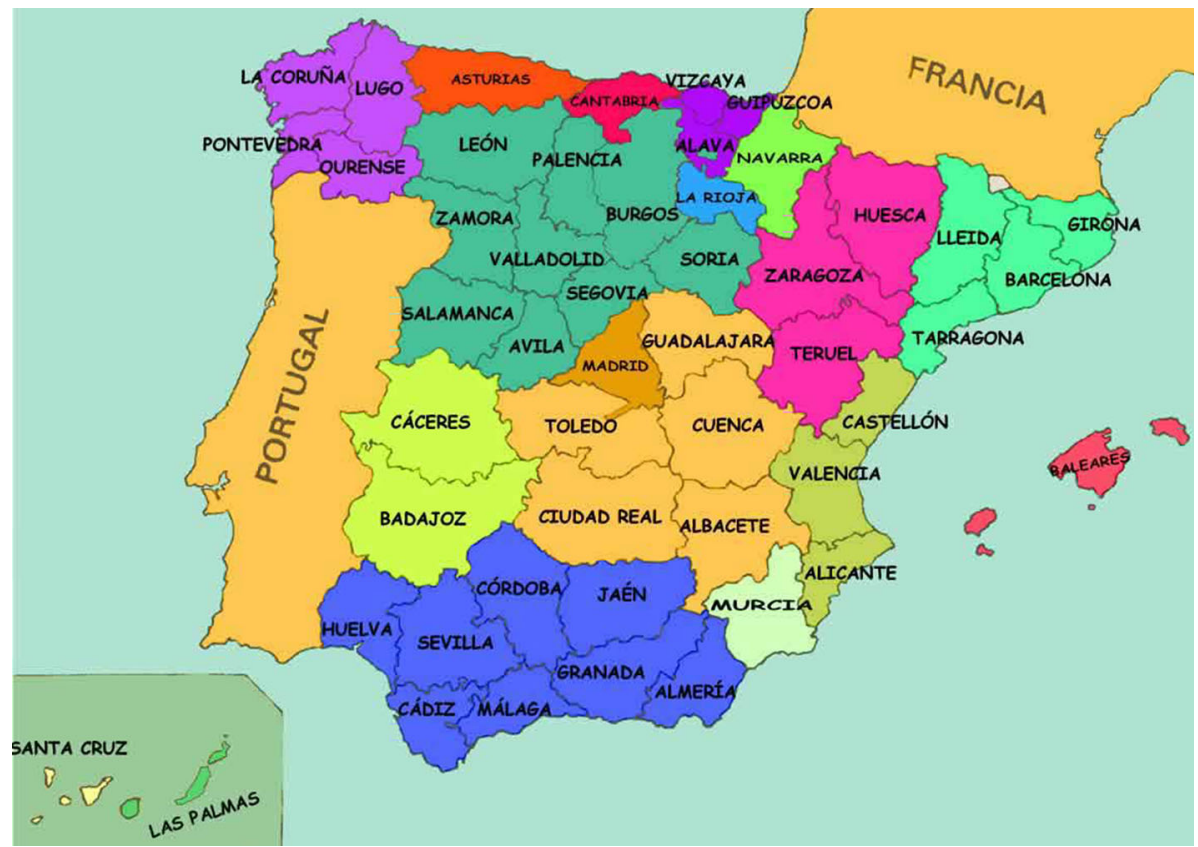

Fig. 1 The administrative organization of Spain into NUTS2 and NUTS3 categories

\subsection{Methods}

Using Shannon's (1948) information theory, uncertainty in the distribution of a random variable $x$ can be defined as $H_{x}=-\sum_{x} p_{x} \log _{2} p_{x}$. The values of $p_{\mathrm{x}}$ are the relative frequencies of $x: p_{x}=f_{x} / \sum_{x} f_{x}$. Using the two-base for the logarithm, uncertainty is expressed in bits.

The uncertainty in the case of a system with two variables can analogously be formulated as

$$
H_{x y}=-\sum_{x} \sum_{y} p_{x y} \log _{2} p_{x y}
$$

In this case of two variables with interaction, the uncertainty of the system is reduced because of mutual information $T_{x y}$ as follows:

$$
T_{x y}=\left(H_{x}+H_{y}\right)-H_{x y}
$$

If the two distributions of $x$ and $y$ are independent, $T_{x y}=0$ and $H_{x y}=\left(H_{x}+H_{y}\right)$. One can derive (e.g., McGill 1954; Abramson 1963, pp. 131 ff.) that in a case of three dimensions - as in the case we will study below-mutual information corresponds to:

$$
T_{x y z}=H_{x}+H_{y}+H_{z}-H_{x y}-H_{x z}-H_{y z}+H_{x y z}
$$

When the negative terms in Eq. 3 are larger than the positive ones, negative entropy is generated. Krippendorff (2009) argued that this formula is therefore inconsistent with Shannon's information theory. The negative entropy is generated by next-order loops in the 
Table 1 NACE classifications (Rev. 2) of high- and medium-tech manufacturing, and knowledge-intensive services. Sources: Eurostat/OECD (2009, 2011); Eurostat/OECD (2011); cf. Laafia (2002, p. 7) and Leydesdorff et al. (2006, p. 186)

High-tech manufacturing

21 Manufacture of basic pharmaceutical products and pharmaceutical preparations

26 Manufacture of computer, electronic and optical products

30.3 Manufacture of air and spacecraft and related machinery

Medium-high-tech manufacturing

20 Manufacture of chemicals and chemical products

25.4 Manufacture of weapons and ammunition 27 Manufacture of electrical equipment,

28 Manufacture of machinery and equipment n.e.c.,

29 Manufacture of motor vehicles, trailers and semi-trailers,

30 Manufacture of other transport equipment excluding 30.1 Building of ships and boats, and

excluding 30.3 Manufacture of air and spacecraft and related machinery

32.5 Manufacture of medical and dental instruments and supplies
Knowledge-intensive sectors (KIS)

50 Water transport,

51 Air transport

58 Publishing activities,

59 Motion picture, video and television programme production, sound recording and music publishing activities,

60 Programming and broadcasting activities,

61 Telecommunications,

62 Computer programming, consultancy and related activities,

63 Information service activities

64 to 66 Financial and insurance activities

69 Legal and accounting activities,

70 Activities of head offices; management consultancy activities,

71 Architectural and engineering activities; technical testing and analysis,

72 Scientific research and development,

73 Advertising and market research,

74 Other professional, scientific and technical activities,

75 Veterinary activities

78 Employment activities

80 Security and investigation activities

84 Public administration and defence, compulsory social security

85 Education

86 to 88 Human health and social work activities,

90 to 93 Arts, entertainment and recreation

Of these sectors, 59 to 63 , and 72 are considered high-tech services.
Table 2 Size distribution of the firms in the sample according to the number of employees. (Source: ORBIS data; 2010.) a In the case of 26,604 records, the number of employees was not available (n.a.) in the ORBIS data set

\begin{tabular}{lrr}
\hline N of employees & N of firms & $\%$ \\
\hline 0,1 or n.a. $^{\text {a }}$ & 276,685 & 27.4 \\
$2-4$ & 359,804 & 35.7 \\
$5-9$ & 183,815 & 18.2 \\
$10-19$ & 99,527 & 9.9 \\
$20-49$ & 58,983 & 5.8 \\
$50-99$ & 15,926 & 1.6 \\
$100-199$ & 7444 & 0.7 \\
$200-499$ & 4428 & 0.4 \\
$500-749$ & 881 & 0.1 \\
$750-999$ & 469 & 0.0 \\
$>1000$ & 1242 & 0.1 \\
Total & $1,009,204$ & 100 \\
\hline
\end{tabular}


communication; for example, when meaning is exchanged or different codes of communication invoked. Each third "partner" in the communication may spuriously feedback or feedforward on the communication between the other two. In other words, a triangle can be tumbled to the right or to the left. Uncertainty can be added or reduced when three dimensions operate by generating mutual information or redundancy, respectively.

Redundancy generation reduces relative uncertainty by providing new options to the system. For example, meanings can be shared or codes of communication operating as selection environments can interact. New redundancy adds options to the system that were hitherto not realized. An innovation system can be prolific in providing new options because the non-linear dynamics can become self-reinforcing (Ulanowicz 2009). The historical realizations then function as a retention mechanism. Increasing the number of its options may be more important for the viability of an innovation system than the options realized hitherto (Fritsch 2004).

Note that the generation of redundancy indicates an interaction among selection environments, whereas the generation of uncertainty is a consequence of variation in historical relations. Our measure, in other words, does not measure action (e.g., academic entrepreneurship) as input or output, but the investment climate as a structural consequence of correlations among distributions of relations. However, the distinction between the structural dynamics and the historical dynamics of relations is analytical. In practice, the two layers reflect each other in an evolving system. Equation 3 models the trade-off between variation and selection as positive and negative contributions to the uncertainty that prevails.

Although this trade-off can also be modeled in terms of the analysis of variance (McGill 1954), the use of information theory has the advantage that all terms are composed from sigmas and therefore the results are fully decomposable to the micro-level. Thus, the measurement model is micro-founded. One can examine empirically how much specific firms, sectors or regions add to the uncertainty or the redundancy. Is emerging systemness at various levels of aggregation sectorial, regional, or otherwise (Carlsson 2006)?

Theil (1972, pp. 20f.), furthermore, showed that in the case of groups (or subsamples), one can decompose the information as follows: $H=H_{0}+\sum_{G} \frac{n_{G}}{N} H_{G}$. The right-hand term $\left(\sum_{G} \frac{n_{G}}{N} H_{G}\right)$ provides the average uncertainty in the groups and $H_{O}$ the additional uncertainty in-between groups. Analogously, one can derive (Leydesdorff and Strand 2013, at p. 1895):

$$
T=T_{0}+\sum_{G} \frac{n_{G}}{N} T_{G}
$$

In this formula, $T_{\mathrm{G}}$ can be considered as a measure of uncertainty at the geographical scale $G ; n_{\mathrm{G}}$ is the number of firms at this scale, and $N$ is the total number of firms under study. One can also decompose across regions or in terms of firm sizes, or in terms of combinations of dimensions.

$$
\Delta T_{G}=\sum_{G} \frac{n_{G}}{N} T_{G}
$$

However, for comparisons across samples one may have to normalize, for example as percentages, because the scales are sample-dependent. ${ }^{6}$ After normalization (Eq. 5), the geographical contributions of regions or provinces can be compared and aggregated. The

\footnotetext{
${ }^{6}$ The maximum entropy $H_{\max }=\log (N)$.
} 
difference between the sum of the normalized contributions $\left(\Sigma_{G} \Delta T_{G}\right)$ and the next-order level can be considered as a surplus generated between the groups $G$.

In this study, we decompose the Spanish innovation system in terms of NUTS2 and NUTS3 regions and then zoom into the relative weights of knowledge-intensive services and high- or medium-tech manufacturing, both at the level of the Spanish system and at the regional levels. In this design, the between-group term $T_{0}$ provides us with a measure of what the national system adds in terms of synergy to the sum of the regional systems (given the sectors under study). The three dimensions are the (g)eographical, ( $\mathrm{t}$ )echnological, and (o)rganizational; synergy will be denoted as $T_{\mathrm{GTO}}$. We express synergy in millibits (mbits); 1 bit $=1000$ mbits.

\section{Results}

\subsection{Regions at the NUTS 2 level}

Figure 2 provides a map of Spain with the regions (NUTS2) colored according to their respective contributions to synergy generation in the Spanish innovation system. The total synergy for Spain is -886 mbits, of which $54.5 \%$ is realized in four regions: Catalonia ( -163 mbits or 18.4\%), Andalusia (13.8\%), the Communidad de Madrid (11.6\%), and the Valencian Community (10.7\%). The between-regions synergy at the national level is only 52 mbits or $5.9 \%$ of the national synergy (Table 3, column c). This is much less than we found in previous studies of national systems (except for Hungary) ${ }^{7}$ : Norway $(11.7 \%$ ), China (18.0\%), the Netherlands (27.1\%), Sweden (20.4\%), and Russia (37.9\%). In other words, the Spanish system does not function as a unified country, but innovation is regionalized (Fig. 4).

In the case of eastern Hungary, Lengyel and Leydesdorff (2011) conjectured that the relatively high synergy value reflected a previous form of, in this case, state-led integration. Perhaps, something similar is the case for Andalusia: there is no synergy in the hightech sector, and the region is also not prominent in medium-high tech. Table 3 shows the values for (1) all sectors; (2) sectors labeled as high-tech manufacturing in Table 1 above; (3) medium-high tech; and (4) knowledge-intensive services. The contribution to the synergy is highest for Catalonia in all the columns. The lead of Catalonia compared to the Community of Madrid - the official name of this region-is most pronounced in mediumhigh tech manufacturing, where Catalonia contributes $32.6 \%$ to the national synergy and Madrid only $11.7 \%$. The national level adds $16.4 \%$ between-regional synergy to this. In high-tech manufacturing, Catalonia (36.2\%) and Madrid (30.0\%) contribute both, but the national level prevails in this sector with $\Delta \mathrm{T}_{0}=37.7 \%$.

Figure 3 shows the percentage contributions to synergy generation for the 19 regions sorted by their contributions to medium-high tech manufacturing. In addition to the Community of Madrid and Catalonia, the Valencian Community, the Basque Country, and Andalusia play a role, but to different extents. Andalusia does not play a significant role in the generation of synergy from high- or medium-tech manufacturing. The Valencian Community and the Basque Country are as important as Madrid for generating synergy from medium-high tech industry, but do not contribute to synergy generation in the hightech sectors. In the knowledge-intensive services, the Madrid region and Catalonia take the lead, followed by Andalusia (13.6\%), the Valencian Community (9.8\%), and the Basque

\footnotetext{
${ }^{7}$ In the Hungarian case, there was no surplus synergy at the national level.
} 


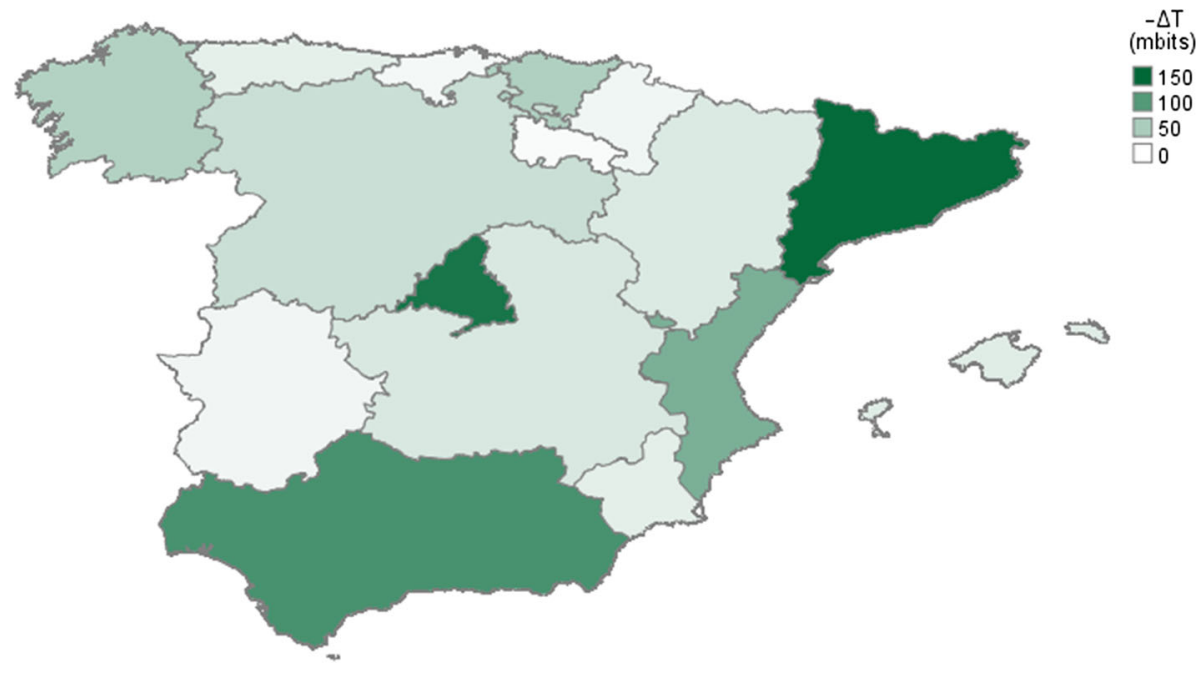

Fig. 2 Synergy generation at the level of 19 regions in Spain (NUTS2). For pragmatic reasons, the Canary Islands are not included in the map; but they are in the Tables

Country $(5.9 \%)$. The between-regional surplus is $6.7 \%$ in this case; that is, of the same order as for "All sectors."

In Table 4, we test whether or to what extent the synergy generation is a function of the number of firms in a region by providing Pearson correlations among firm numbers and synergy generation for the four sectorial categories distinguished in Table 3 . In the top left quadrant, one sees that the numbers of firms in all four categories are significantly correlated. The lowest correlation is for the number of firms in medium-tech manufacturing versus knowledge-intensive services. While medium-tech manufacturing is more strongly oriented towards the local economy than high-tech, knowledge-intensive services tend to be mobile and therefore relatively independent of their geographical location.

Following the first row in Table 4 to the right, we see that the number of firms is not significantly correlated with the synergy produced in All Sectors or in KIS. (The minus sign is generated by the negative values of T.) However, the numbers of firms in HT and MHT are significantly correlated to the generation of synergy. In other words, the presence of HT firms is associated with synergy $(r=.785 ; p<.01)$, etc. In the case of KIS, this correlation is .073 (n.s.) and for All Sectors it is only .004 (n.s.). In summary, the relation between synergy production and geographic localization is sectorially specific: while this relation is significant for HT Manufacturing in the case of Spain, it is virtually absent for KIS. KIS moves easily between regions and is relatively independent of location (Vernon 1979). A knowledge-intensive service can be offered nation-wide.

The bottom right quadrant informs us that the generation of synergy at the level of the economy ("All Sectors") is negatively correlated to the generation of synergy in HT $(r=-.358$; n.s.), but it is positively correlated to synergy generation in MHT $(r=.389$; n.s.) and KIS $(r=.889 ; p<.01)$. Synergy generation in HT and MHT are also correlated $(r=.559 ; p<.05)$. Note that the number of HT firms in the sample is only 2,562 or $2.5 \%$. 


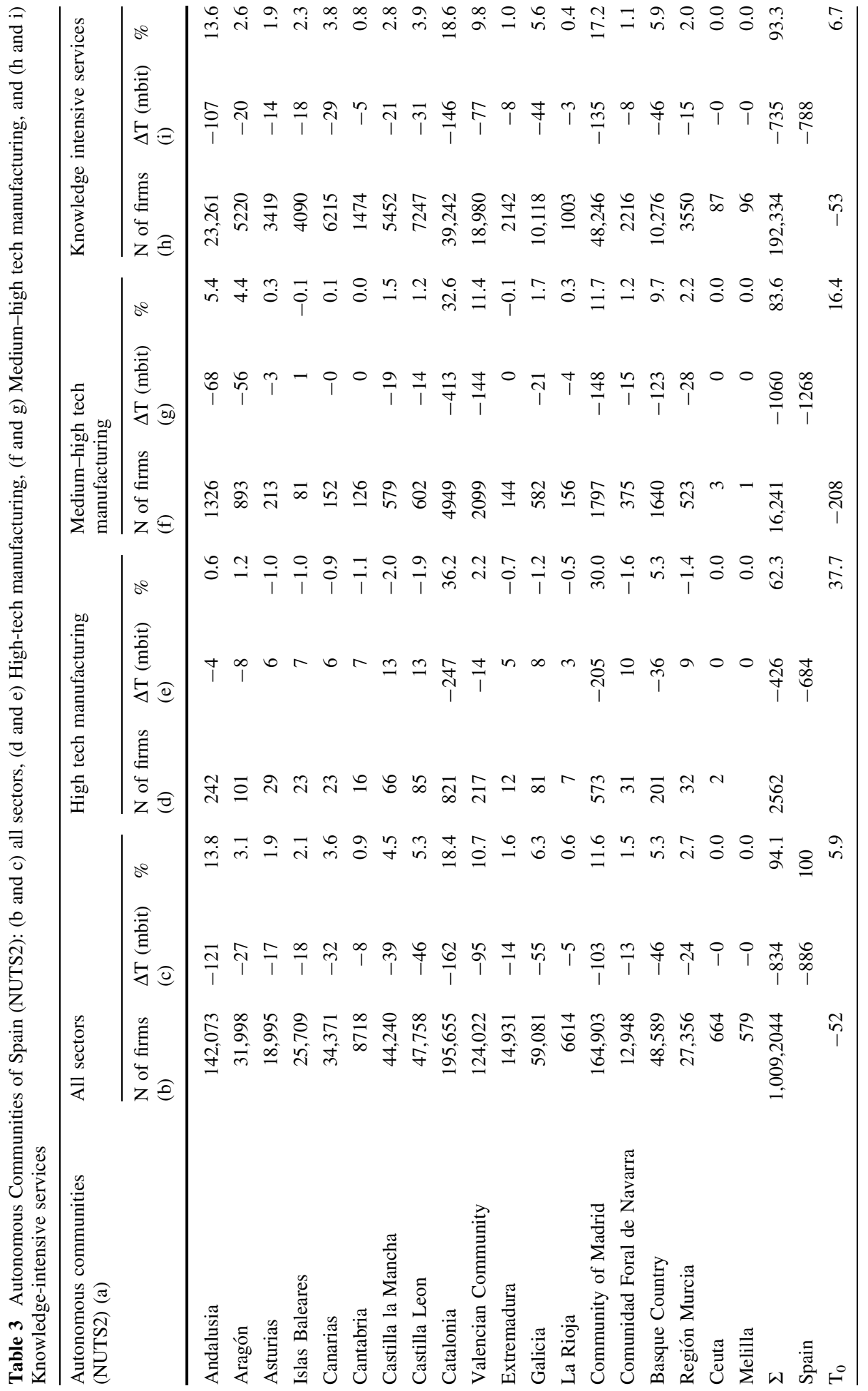




\subsection{The NUTS3 level ("Provincias")}

We repeated the analysis for the 51 provinces of Spain categorized as NUTS3 - that is, the city level. Table 5 shows the results in a format similar to Table 3 . Figure 4 provides the geographical results for each province analogously to Figure 2 at the level of regions. The

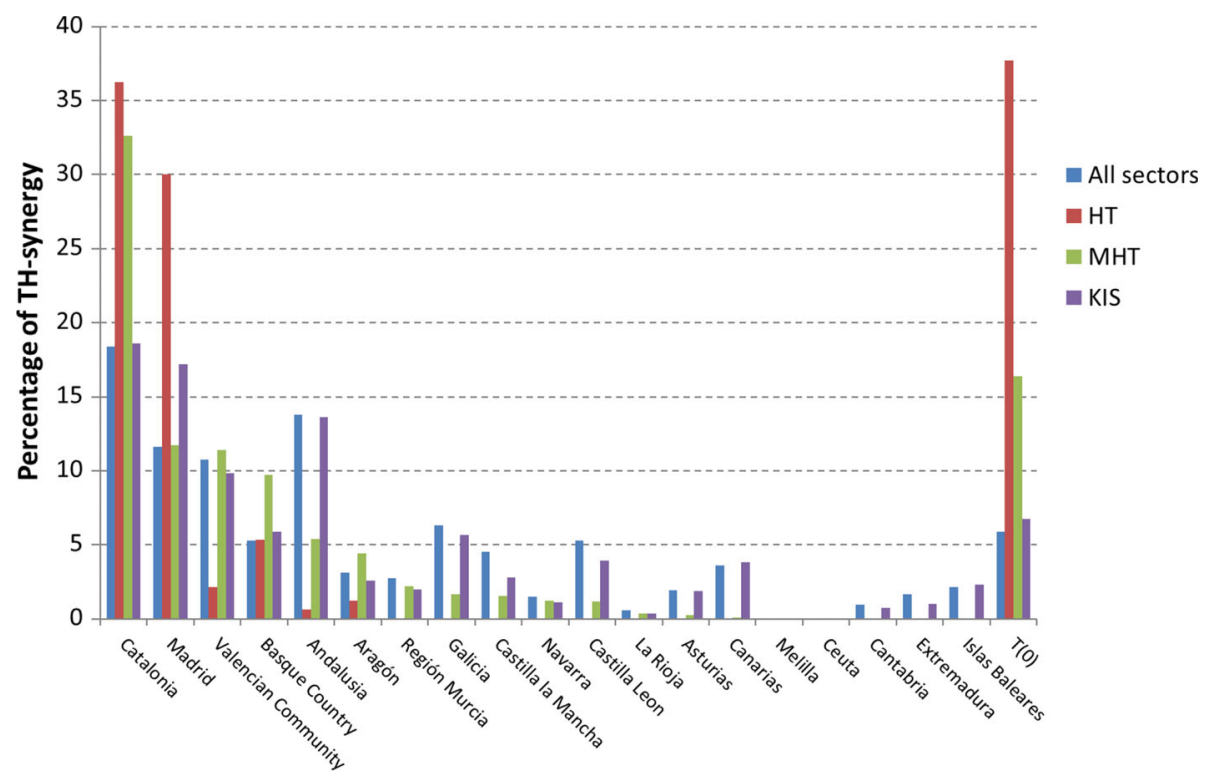

Fig. 3 Contributions to the generation of synergy by 19 Spanish regions (NUTS2 level) in decreasing order

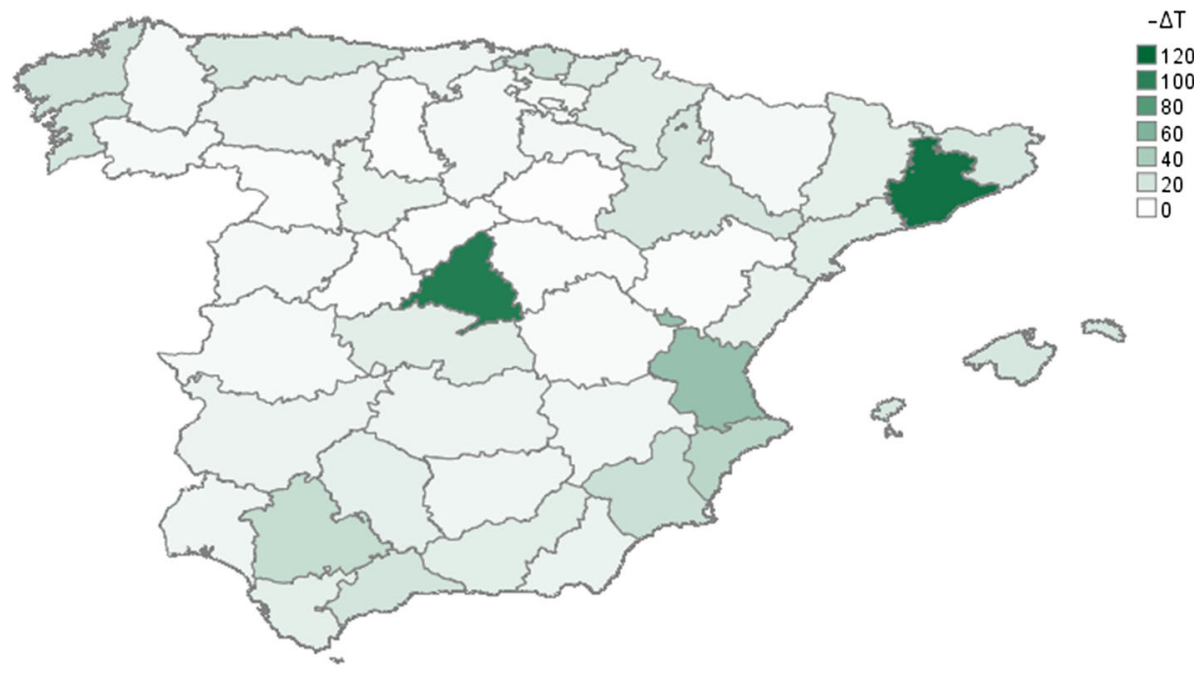

Fig. 4 Synergy contributions of the provinces (NUTS3) to the Spanish innovation system 
Table 4 Correlations between the numbers of firms and synergy generation in Spanish regions and relevant sectors

$\begin{array}{ll}\mathrm{N} \text { of firms } & \begin{array}{l}\mathrm{T} \text { in three dimensions (synergy } \\ \text { indicator) }\end{array}\end{array}$

\begin{tabular}{|c|c|c|c|c|c|c|}
\hline $\begin{array}{l}\text { All } \\
\text { sectors }\end{array}$ & HT & MHT & KIS & $\begin{array}{l}\text { All } \\
\text { sectors }\end{array}$ & HT & MHT \\
\hline
\end{tabular}

$\mathrm{N}$ of firms

All sectors

$\begin{array}{lllllllll}\text { Pearson correlation } & 1 & .916^{* *} & .868^{* *} & .953^{* *} & -.004 & -.722 * * & -.696^{* *} & -.190 \\ \text { Sig. (2-tailed) } & & .000 & .000 & .000 & .988 & .000 & .001 & .435 \\ \mathrm{~N} & 19 & 18 & 19 & 19 & 19 & 19 & 19 & 19 \\ \mathrm{HT} & & & & & & & & \\ \text { Pearson correlation } & .916^{* *} & 1 & .934^{* *} & .935^{* *} & .135 & -.785^{* *} & -.657^{* *} & .040 \\ \text { Sig. (2-tailed) } & .000 & & .000 & .000 & .595 & .000 & .003 & .876 \\ \mathrm{~N} & 18 & 18 & 18 & 18 & 18 & 18 & 18 & 18 \\ \text { MHT } & & & & & & & & 18 \\ \text { Pearson correlation } & .868^{* *} & .934^{* *} & 1 & .799 * * & -.056 & -.705^{* *} & -.707 * * & -.139 \\ \text { Sig. (2-tailed) } & .000 & .000 & & .000 & .821 & .001 & .001 & .569 \\ \text { N } & 19 & 18 & 19 & 19 & 19 & 19 & 19 & 19 \\ \text { KIS } & & & & & & & & \\ \text { Pearson correlation } & .953^{* *} & .935^{* *} & .799 * * & 1 & .084 & -.749 * * & -.667 * * & -.073 \\ \text { Sig. (2-tailed) } & .000 & .000 & .000 & & .733 & .000 & .002 & .767 \\ \text { N } & 19 & 18 & 19 & 19 & 19 & 19 & 19 & 19\end{array}$

$\mathrm{T}$ in three dimensions

All sectors

$\begin{array}{lllllllll}\text { Pearson correlation } & -.004 & .135 & -.056 & .084 & 1 & -.358 & .389 & .889 * * \\ \text { Sig. (2-tailed) } & .988 & .595 & .821 & .733 & & .132 & .099 & .000 \\ \mathrm{~N} & 19 & 18 & 19 & 19 & 19 & 19 & 19 & 19 \\ \mathrm{HT} & & & & & & & & \\ \text { Pearson correlation } & -.722^{* *} & -.785^{* *} & -.705^{* *} & -.749 * * & -.358 & 1 & .559^{*} & -.210 \\ \text { Sig. (2-tailed) } & .000 & .000 & .001 & .000 & .132 & & .013 & .387 \\ \mathrm{~N} & 19 & 18 & 19 & 19 & 19 & 19 & 19 & 19\end{array}$

MHT

\begin{tabular}{lllllllll} 
Pearson correlation & $-.696^{* *}$ & $-.657^{* *}$ & $-.707^{* *}$ & $-.667^{* *}$ & .389 & $.559^{*}$ & 1 & .436 \\
Sig. (2-tailed) & .001 & .003 & .001 & .002 & .099 & .013 & & .062 \\
$\mathrm{~N}$ & 19 & 18 & 19 & 19 & 19 & 19 & 19 & 19 \\
KIS & & & & & & & & \\
Pearson correlation & -.190 & .040 & -.139 & -.073 & $.889 * *$ & -.210 & .436 & 1 \\
Sig. (2-tailed) & .435 & .876 & .569 & .767 & .000 & .387 & .062 & \\
N & 19 & 18 & 19 & 19 & 19 & 19 & 19 & 19 \\
\hline
\end{tabular}

** Correlation is significant at the 0.01 level (2-tailed)

* Correlation is significant at the 0.05 level (2-tailed) 
synergy for Spain is again -886 mbits. The provinces of Barcelona and Madrid realize $12.6 \%$ and $11.6 \%$, respectively. Valencia and Alicante, both part of the Valencian Community, follow with $5.5 \%$ and $3.7 \%$, respectively. Seville ranks fifth with $3.0 \%$ of the synergy.

Twenty-three provinces provide each less than one percent of the synergy. Soria $(-1$ mbits), Avila ( -1 mbits), and Palencia ( -1 mbits) located in the province of Castile and León, along with Teruel ( -2 mbits) form a non-innovative belt around Madrid. The surplus $T_{0}$ between provinces is $12.0 \%$, of which $5.9 \%$ is realized above the regional level (between regions and the nation; see Table 3) and, consequently, $6.1 \%$ between provinces and regions. In other words, the regional level adds as much synergy to the sum of the provinces $(6.1 \%)$ as the nation does to the sum of the regions $(5.9 \%)$. In a regionalized innovation system, however, one would expect more synergy at the regional level between provinces than between the nation and the regions. Note that the sector breakdowns are rather similar in Table 5, with no real differences across sectors.

Figure 5 shows the generation of synergy by the provinces in decreasing order and broken down in terms of sectors. Only the first 12 provinces are shown. At this more finely grained geographical scale of NUTS3, however, the innovation system is as concentrated as at the regional level. The synergy generation in Catalonia as a region is realized in Barcelona to such an extent that, in our opinion, Barcelona can be considered as a metropolitan innovation system. Note that measured at this finer-grained level, the between-regional surplus at the national level is considerable in all four categories. However, there are also considerable differences across sectors. It is much weaker for KIS than for HT and MHT manufacturing.

The two metropoles (Barcelona and Madrid) function both nationally and regionally as the generators of opportunities for innovation. Zaragoza and Seville play comparable roles in their regional environments, but at a much lower level. The Valencian CommunityValencia and Alicante — and the Basque Country_Alava, Bizkaia, and Gipuzkoa—can be considered as regional innovation systems that are spread over provinces, but their synergy levels are much lower than for the two metropoles.

In summary, the Spanish innovation system is regionalized. More than the center in Madrid, Barcelona and Valencia carry the system along the mediterranean coastline. On the Atlantic coast, the Basque Country connects to both France and Spain. In the south, Andalusia has a function in itself, but this innovation system is not high-tech or knowledge-based and is focused in Seville. The remainder of the country is rather barren in terms of generating opportunities for innovation. The two metropoles (Barcelona and Madrid) set the stage. This pattern is reinforced in the case of high-tech or knowledge-intensity.

\section{Discussion and limitations}

The main constraint of this analysis is obviously the use of ORBIS data. Unfortunately, we did not have access to the full data at Statistics Spain such as we obtained from the Scandinavian offices and from Statistics Italy (but not from the Russian Federation or China). The quality of ORBIS data is beyond our control. Given the statistical character of the study, however, the results may still be reliable. In a previous study of Italy, we could use both ORBIS data $(N$ of firms $=462,316)$ and full data from Statistics Italy $(N$ of firms $=4,480,473)$. The results at the NUTS2 level rank-correlated more than $99 \%$ (Spearman's $\rho=.998 ; p<.01$; Cucco and Leydesdorff 2013). This significant correlation 


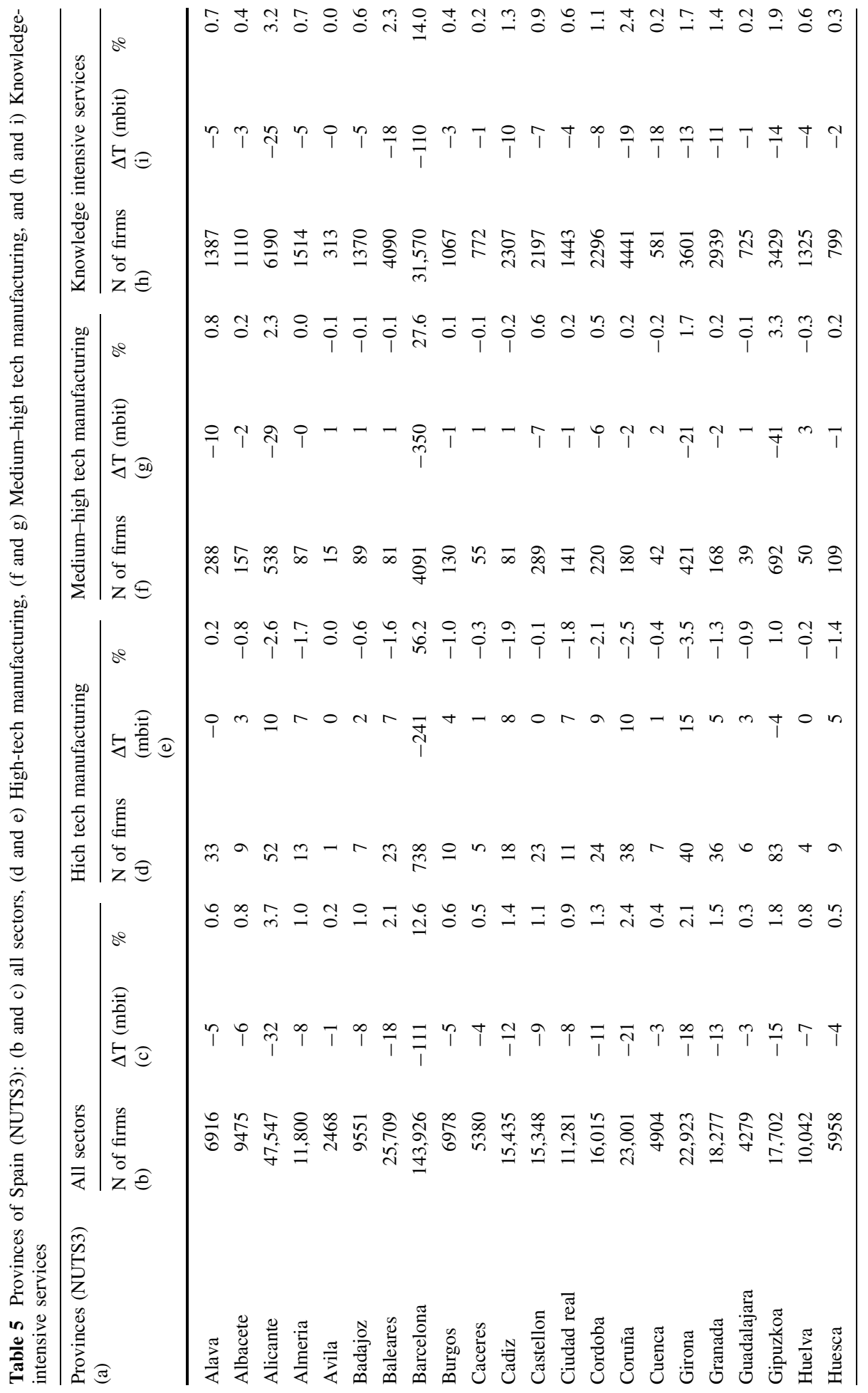




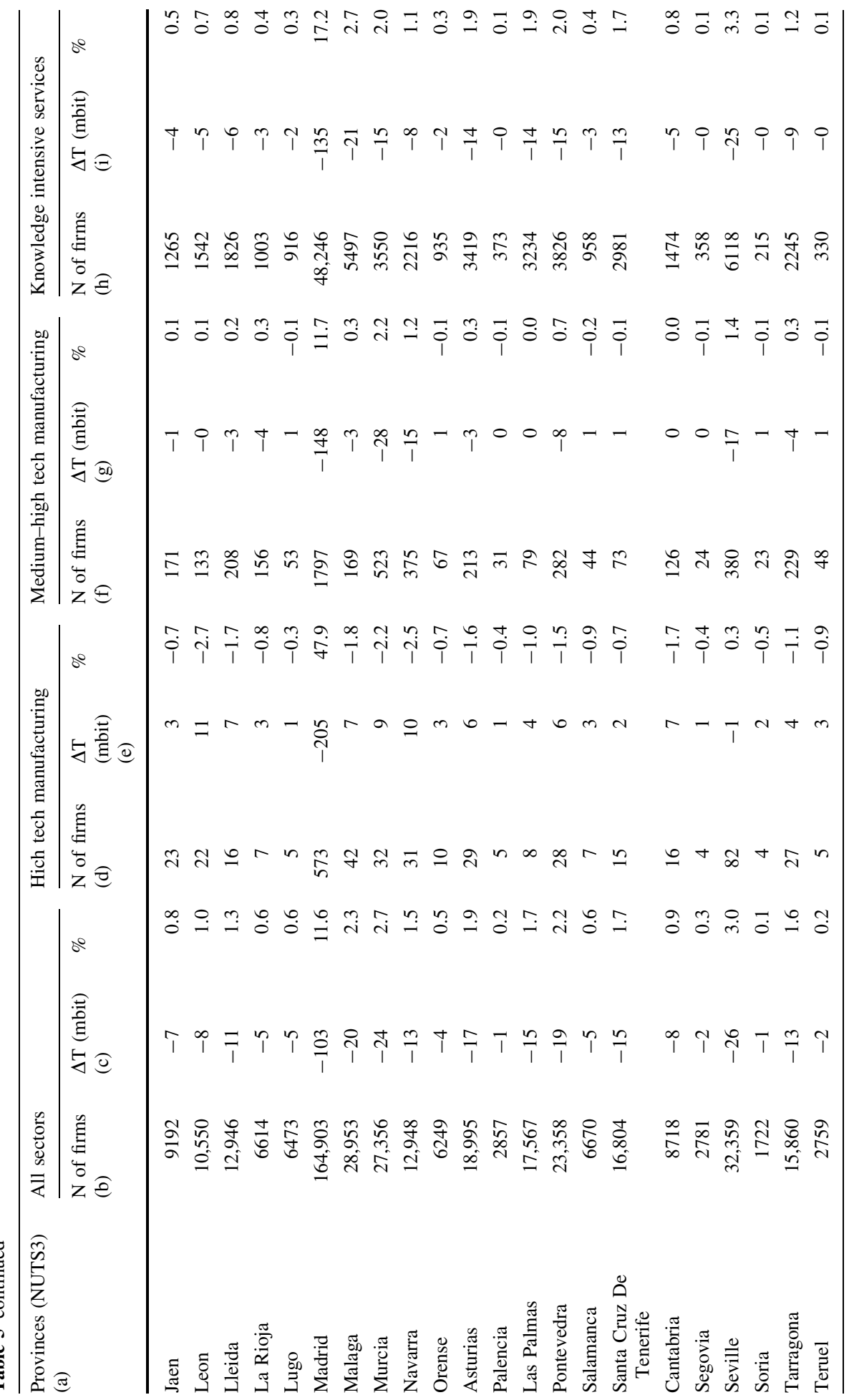




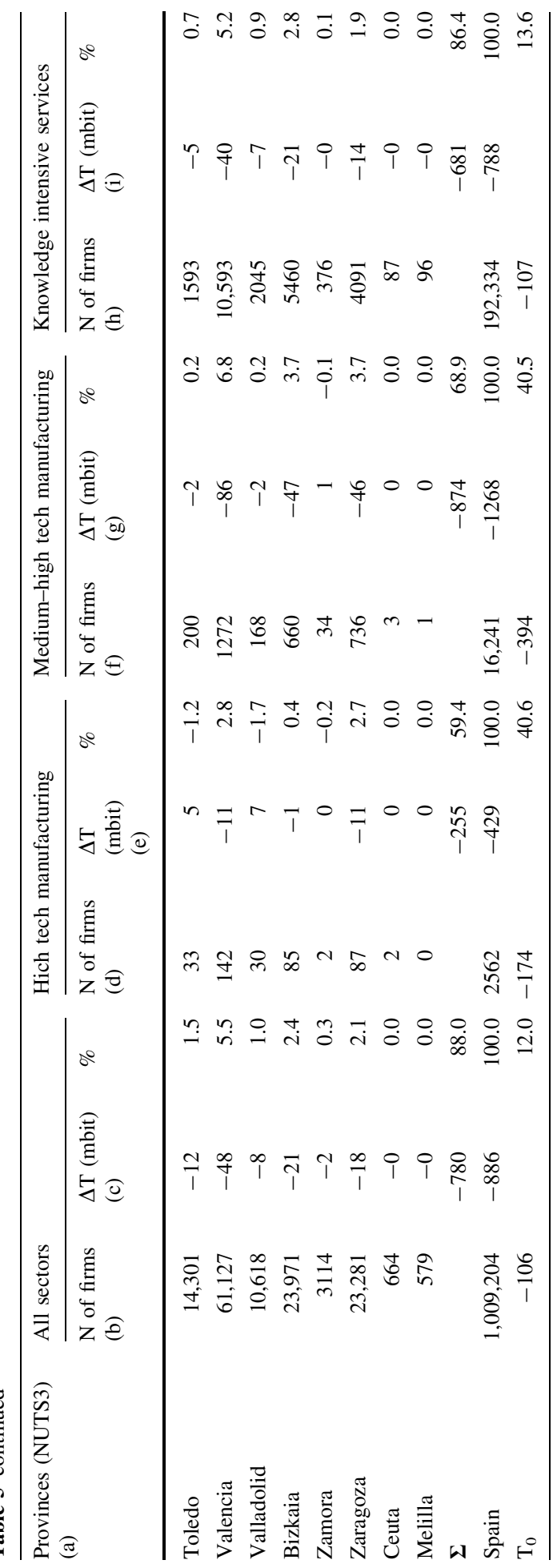




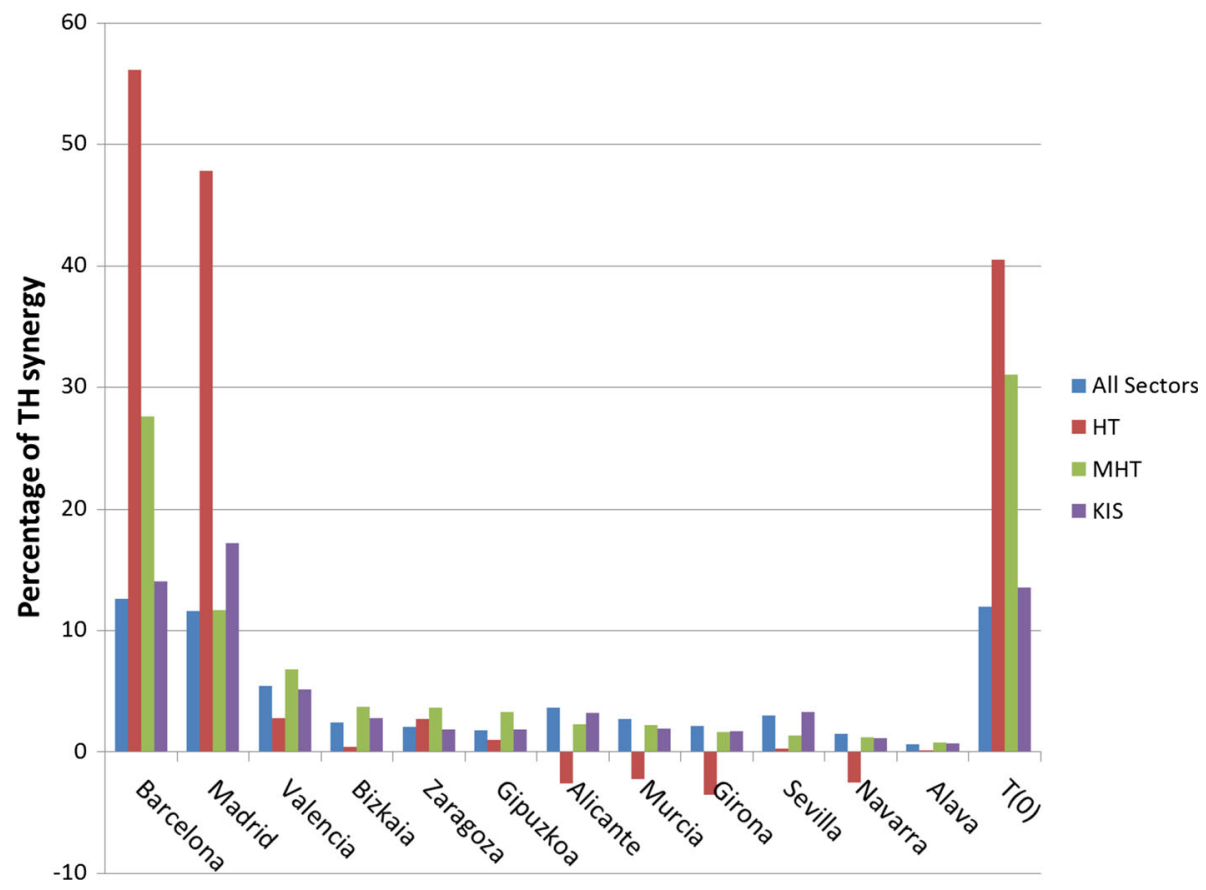

Fig. 5 Contributions to the generation of synergy by 12 (among 51) Spanish provinces in decreasing order

inspires some confidence in using ORBIS data for this purpose. However, the numbers are sometimes small, particularly in disaggregated subsamples such as the number of high-tech manufacturing firms in NUTS3 regions. A further limitation of ORBIS data is the use of primary NACE codes, whereas firms may have been attributed more than a single NACE code.

Using a number of sources, Buesa et al. (2015, pp. 78 ff.) collected similar data about Spanish firms for an input-output Data Envelopment Analysis. (Unfortunately, the number of firms in the sample was not specified.) The efficiency of the regional innovation systems in Spain was analyzed at the NUTS2 level of regions for the same year (2010). On the basis of an analysis without sectorial differentiation, the best performance was indicated for Catalonia (100\%), the Community of Madrid (100\%), and Navarra (100\%), followed by Aragon (99\%) and the Valencian Community (95\%). When the analysis was repeated for high-tech manufacturing, the best results were obtained for Aragon (97\% efficiency), followed by La Rioja (87\%), Navarra (80\%), and the Basque Country (73\%). Madrid was only $70 \%$ efficient and Catalonia $60 \%$.

Focusing on high-tech firms, Zabala-Iturriagagoitia et al. (2007) report leading roles for Catalonia and the Community of Madrid, with the Basque Country as a significant third region. However, Andalusia would be positioned at the bottom, after the Balearic Island, Extremadura, Castille-La Mancha, and Murcia. From another perspective, Navarro and Gibaja (2012) and Alberdi Pons et al. (2014) analyze the types of regional innovation systems in Spain. According to these authors, the Basque Country, Navarre, Catalonia, and the Community of Madrid would work as cohesive innovation systems, while the Canary and Balearic Islands, Andalusia, both Castilles, Asturias, Galicia, Murcia, Extremadura, and Cantabria are considered as fragmented RIS. Focusing on biotechnology, Diaz et al. 
(2002) points to Catalonia and the Community of Madrid as the metropoles. Andalusia, Galicia, and the Valencian Community follow with more scattered portfolios.

Obviously, these results are in many respects different from ours. The differences may be generated both by different sources and by using different methods. We focus on firms as units of analysis, while the other studies included other knowledge producers such as the creators of new patents, publications, or subsidies for research projects. Nevertheless, the message of these authors is the same: Madrid and Barcelona are the innovative powerhouses of Spain. According to these authors, however, this would be less the case for hightech manufacturing. Our analysis does not confirm this result. Furthermore, in their results the regions play a role that is more central than in ours.

Note that our analysis focuses on the possible interactions among the structural dimensions of innovation systems operating as selection environments. Redundancy generated at this structural level is traded off against uncertainty generation in historical relations (Eq. 3 above). Buesa et al. (2015) and the other studies focused on the efficiency in the historical variation and not on the potential of regions and cities to develop new options for innovation as systems. Thus, the research questions are also very different.

\section{Conclusions}

Two metropolitan innovation systems are central: Barcelona and Madrid. On most indicators of synergy production Barcelona scores above Madrid. The exception is KIS, which is more synergetic in Madrid than Barcelona. This may be an effect of the state apparatuses being centralized in Madrid and requiring knowledge-intensive services. Otherwise, our results do not indicate strong regionalization of the Spanish innovation system. The relatively pronounced role of Andalusia as a regional innovation system at a level comparable to the Valencian Community and the Basque Country was not expected.

We conjecture that Andalusia has a pattern of integration comparable to eastern Hungarian regions that were also successful in maintaining specific characteristics from the past that are still functional. The Andalusian system is heavily concentrated in Seville as a semi-metropole. The other two regions-the Valencian Community and the Basque Country — can be considered as regional innovation systems, but they provide options for innovation at a much lower rate than Barcelona and Madrid.

Returning to our research questions and methods, we may conclude that the betweenregional (that is, national) surplus in redundancy is low when compared with other European nations; but the conclusion is not that the weakness of the national innovation system has led to strong regional innovation systems. The regionalization is mainly driven by the two metropoles which are at the center of a metropolitan innovation system. Andalusia, the Basque Country, and the Valencian Community can perhaps be considered as regional innovation systems, albeit with far fewer options than the metropolitan systems; the remainder of the country has hitherto remained peripheral in terms of the development of a knowledge-based economy. Given the policy objective of regionalization (among other things) expressed in the new constitution of 1978, these results may appear disappointing.

At the theoretical level, our contribution is mainly an empirical and methodological one. We have wished to show that the question of regionalization of national systems of innovation can be operationalized in terms of synergy production at the various levels. Furthermore, our argument is that innovation systems should not be inferred from the 
behavior of entrepreneurs and enterprises. From a systems perspective, behavior ("action") provides the (potentially stochastic) variation. The system operates deterministically in terms of selection environments, but the latter change historically and under pressure from relevant variation.

Selection environments are not given, but they can be specified. Two selection environments operating upon each other may lead to co-evolution and potentially lock-in along historical trajectories. Three selection environments operating upon one another, however, may lead to reinforcements and loops among feedback loops. The interactions among the selection environments can then be expected to generate redundancies which counteract the variation. This is not a linear process that can be steered by providing the right input, but a process of self-organization and emergence. The political intervention is then in need of being reflexively informed about its intended and unintended consequences (Leydesdorff et al., 2017; Petersen et al. 2016). The methodological objective of this study has been to measure this process without reducing the complexity to indicators of historical variation (Ashby 1964).

Acknowledgements We are grateful to the anonymous referee for constructive comments.

Open Access This article is distributed under the terms of the Creative Commons Attribution 4.0 International License (http://creativecommons.org/licenses/by/4.0/), which permits unrestricted use, distribution, and reproduction in any medium, provided you give appropriate credit to the original author(s) and the source, provide a link to the Creative Commons license, and indicate if changes were made.

\section{References}

Abramson, N. (1963). Information theory and coding. New York: McGraw-Hill.

Alberdi Pons, X., Gibaja Martíns, J. J., \& Davide Parrilli, M. (2014). Evaluación de la fragmentación en los Sistemas Regionales de Innovación: Una tipología para el caso de España. Investigaciones Regionales, 1(28), 7-35.

Ashby, W. R. (1964). Constraint analysis of many-dimensional relations. General Systems Yearbook, 9 , 99-105.

Balconi, M., Breschi, S., \& Lissoni, F. (2004). Networks of inventors and the role of academia: an exploration of Italian patent data. Research Policy, 33(1), 127-145.

Biggiero, L. (1998). Italian industrial districts: a triple helix pattern of problem solving. Industry and Higher Eductation, 12(4), 227-234.

Boschma, R. (2005). Proximity and innovation: a critical assessment. Regional Studies, 39(1), 61-74.

Braczyk, H.-J., Cooke, P., \& Heidenreich, M. (Eds.). (1998). Regional innovation systems. London/Bristol PA: University College London Press.

Brooks, D. R., \& Wiley, E. O. (1986). Evolution as entropy. Chicago/London: University of Chicago Press.

Buesa, M., Heijs, J., Baumert, T., \& Gutiérrez Rojas, C. (2015). La eficiencia de los sistemas regionales de innovación en España y sus determinantes. Madrid: Libro editado por la Fundación de las Cajas de Ahorro (FUNCAS).

Buesa, M., Heijs, J., Pellitero, M. M., \& Baumert, T. (2006). Regional systems of innovation and the knowledge production function: the Spanish case. Technovation, 26(4), 463-472.

Carboni, O. A. (2013). Spatial and industry proximity in collaborative research: evidence from Italian manufacturing firms. The Journal of Technology Transfer, 38(6), 896-910.

Carlsson, B. (2006). Internationalization of innovation systems: A survey of the literature. Research Policy, $35(1), 56-67$.

Cooke, P. (2002). Knowledge Economies. London: Routledge.

Cooke, P., \& Leydesdorff, L. (2006). Regional development in the knowledge-based economy: The construction of advantage. Journal of Technology Transfer, 31(1), 5-15. doi:10.1007/s10961-005-5009-3.

Cooke, P. \& Morgan, K. (1992) Regional Innovation Centres in Europe: The Experience of the Basque Country, Emilia-Romagna and Wales. Regional Industrial Research Report 11. Cardiff: Department of City \& Regional Planning, University of Wales College of Cardiff. 
Cucco, I., \& Leydesdorff, L. (2013). Measuring synergies in the Italian innovation system: A comparison of Amadeus $^{\mathrm{TM}}$ and administrative data. Paper presented at the the Wageningen International Conference on Networks and Management. Capri, June 2013.

DÍaz, V., Muñoz, E., de los Monteros, J. E., \& Senker, J. (2002). The socio-economic landscape of biotechnology in Spain. A comparative study using the innovation system concept. Journal of Biotechnology, 98(1), 25-40.

Edquist, C. (Ed.). (1997). Systems of Innovation: Technologies, Institutions and Organizations. London: Pinter.

Eurostat/OECD. (2011). High technology and knowledge-intensive sectors, December 2011. Available at http://epp.eurostat.ec.europa.eu/cache/ITY_SDDS/Annexes/hrst_st_esms_an9.pdf.

Freeman, C. (1987). Technology, policy, and economic performance: lessons from Japan. London: Pinter Publishers.

Freeman, C. (1988). Japan, a new system of innovation. In G. Dosi, C. Freeman, R. R. Nelson, G. Silverberg, \& L. Soete (Eds.), Technical change and economic theory (pp. 330-348). London: Pinter.

Fritsch, M. (2004). Cooperation and the efficiency of regional R\&D activities. Cambridge Journal of Economics, 28(6), 829-846.

Ivanova, I. A., \& Leydesdorff, L. (2014). Redundancy generation in university-industry-government relations: The triple helix modeled, measured, and simulated. Scientometrics, 99(3), 927-948. doi:10.1007/ s11192-014-1241-7.

Kauffman, S. A. (2000). Investigations. Oxford: Oxford University Press.

Knoben, J., \& Oerlemans, L. A. (2006). Proximity and inter-organizational collaboration: A literature review. International Journal of Management Reviews, 8(2), 71-89.

Krippendorff, K. (2009). W. Ross Ashby's information theory: a bit of history, some solutions to problems, and what we face today. International Journal of General Systems, 38(2), 189-212.

Laafia, I. (2002). National and regional employment in high tech and knowledge intensive sectors in the EU-1995-2000. In Statistics in focus: Science and technology, Theme 9 (3), http://epp.eurostat.ec. europa.eu/cache/ITY_OFFPUB/KS- NS- 02- 003/EN/KS- NS- 02- 003- EN.PDF

Lengyel, B., \& Leydesdorff, L. (2011). Regional innovation systems in Hungary: The failing synergy at the national level. Regional Studies, 45(5), 677-693. doi:10.1080/00343401003614274.

Leydesdorff, L. (2003). The mutual information of university-industry-government relations: An indicator of the triple helix dynamics. Scientometrics, 58(2), 445-467.

Leydesdorff, L., Dolfsma, W., \& Van der Panne, G. (2006). Measuring the knowledge base of an economy in terms of triple-helix relations among 'technology, organization, and territory'. Research Policy, 35(2), 181-199.

Leydesdorff, L., Etzkowitz, H., Ivanova, I., \& Meyer, M. (2017). The measurement of synergy in innovation systems: Redundancy generation in a triple helix of university-industry-government relations. In W. Glänzel, H. Moed, U. Schmoch, \& M. Thelwall (Eds.), Springer handbook of science and technology indicators. Heidelberg: Springer.

Leydesdorff, L., \& Oomes, N. (1999). Is the European monetary system converging to integration? Social Science Information, 38(1), 57-86.

Leydesdorff, L., \& Strand, Ø. (2013). The Swedish system of innovation: Regional synergies in a knowledge-based economy. Journal of the American Society for Information Science and Technology, 64(9), 1890-1902.

Lundvall, B.-Å. (1988). Innovation as an interactive process: from user-producer interaction to the national system of innovation. In G. Dosi, C. Freeman, R. Nelson, G. Silverberg, \& L. Soete (Eds.), Technical change and economic theory (pp. 349-369). London: Pinter.

Lundvall, B.-A․ (Ed.). (1992). National systems of innovation. London: Pinter.

McGill, W. J. (1954). Multivariate information transmission. Psychometrika, 19(2), 97-116.

Moso, M., \& Olazaran, M. (2002). Regional technology policy and the emergence of an R\&D system in the Basque country. Journal of Technology Transfer, 27(1), 61-75.

Navarro, M., \& Gibaja, J. J. (2012). Typologies of innovation based on statistical analysis for European and Spanish regions. In B. Asheim, \& M. Parrilli (Eds.), Interactive learning for innovation (pp. 234-274). London, UK: Palgrave Macmillan.

Nelson, R. R. (Ed.). (1993). National innovation systems: A comparative analysis. New York: Oxford University Press.

Nelson, R. R., Buterbaugh, K., Perl, M., \& Gelijns, A. (2011). How medical know-how progresses. Research Policy, 40(10), 1339-1344.

Nelson, R. R., \& Winter, S. G. (1982). An evolutionary theory of economic change. Cambridge, MA: Belknap Press of Harvard University Press. 
Oh, D.-S., Phillips, F., Park, S., \& Lee, E. (2016). Innovation ecosystems: A critical examination. Technovation, 54, 1-6.

Petersen, A., Rotolo, D., \& Leydesdorff, L. (2016). A triple helix model of medical innovations: Supply, demand, and technological capabilities in terms of medical subject headings. Research Policy, 45(3), 666-681. doi:10.1016/j.respol.2015.12.004.

Riba-Vilanova, M., \& Leydesdorff, L. (2001). Why Catalonia cannot be considered as a regional innovation system? Scientometrics, 50(2), 215-240.

Ritala, P., \& Almpanopoulou, A. (2017). In defense of 'eco'in innovation ecosystem. Technovation (in press).

Rocha, F. (1999). Inter-firm technological cooperation: Effects of absorptive capacity, firm-size and specialization. Economics of Innovation and New Technology, 8(3), 253-271.

Schumpeter, J. ([1939], 1964). Business cycles: A theoretical, historical and statistical analysis of capitalist process. New York: McGraw-Hill.

Schwartz, D. (2006). The regional location of knowledge based economy activities in Israel. The Journal of Technology Transfer, 31(1), 31-44.

Shannon, C. E. (1948). A mathematical theory of communication. Bell System Technical Journal, 27, 379-423.

Storper, M. (1997). The regional world-territorial development in a global economy. New York: Guilford Press.

Theil, H. (1972). Statistical decomposition analysis. Amsterdam/London: North-Holland.

Ulanowicz, R. E. (2009). The dual nature of ecosystem dynamics. Ecological Modelling, 220(16), 1886-1892.

Vernon, R. (1979). The product cycle hypothesis in a new international environment. Oxford Bulletin of Economics and Statistics, 41(4), 255-267.

Woerter, M. (2012). Technology proximity between firms and universities and technology transfer. The Journal of Technology Transfer, 37(6), 828-866.

Zabala-Iturriagagoitia, J. M., Voigt, P., Gutiérrez-Gracia, A., \& Jiménez-Sáez, F. (2007). Regional innovation systems: How to assess performance. Regional Studies, 41(5), 661-672. 